\title{
Trabalhar em serviços destinados a pessoas em situação de sem-abrigo ${ }^{1}$
}

Recensão

\author{
Alda Teixeira Gonçalves ${ }^{2}$ \\ Gabinete de Estudos e Planeamento, Ministério do Trabalho, Solidariedade e Segurança Social e \\ DINÂMIA'CET-Iscte, Portugal
}

\begin{abstract}
"In the future, the year 2020 will always have a given place in the History Books. It was the year in which each country's resources, its crisis organisations and, not least, the responsibility of each individual was put to the test. Not in modern times have we experienced a pandemic with such an impact as the current Covid-19 pandemic." (Baptista et al., 2020, p. 5)
\end{abstract}

Esta pesquisa, com o título Staffing Homelessness Services in Europe, constitui o décimo estudo comparativo promovido pelo European Observatory on Homelessness/FEANTSA e foi efetuado com base nos resultados de um questionário dirigido a peritos de 15 Estados-Membros da UE ${ }^{3}$ (Bélgica, Croácia, República Checa, Dinamarca, Finlândia, Alemanha, Grécia, Hungria, Itália, Holanda, Polónia, Portugal, Eslovénia, Espanha e Reino Unido).

O objectivo central da investigação foi o de analisar as práticas dos trabalhadores que prestam serviços a pessoas em situação de sem-abrigo. Centrou-se, portanto, em serviços específicos que proporcionam alojamentos, desde abrigo de emergência e habitação com pessoal de apoio no local, até à provisão de habitação comum e independente e ao modelo Housing First. Contudo, ao ser efetuada durante a emergência da pandemia COVID 19, a pesquisa permitiu também dar conta do seu impacte inicial quer nas equipas, quer na organização e na prestação de serviços às pessoas em situação de sem-abrigo, nos 15 países europeus. Temática bastante atual e pertinente.

Como referem os autores, o presente estudo integra-se num conjunto de pesquisas comparativas, focadas na diversidade e extensão da prestação de serviços dirigidos a pessoas em situação de sem-abrigo, respectiva regulamentação e qualidade desses serviços na Europa.

Encontra-se estruturado em oito pontos, iniciando com uma síntese das principais questões analisadas; seguindose uma abordagem de enquadramento relativamente às práticas dos prestadores de serviços, dirigidos a pessoas em situação de sem-abrigo, referindo as questões centrais da pesquisa, assim como a metodologia utilizada, baseada num inquérito por questionário; o terceiro ponto dá conta das práticas e dificuldades enfrentadas pelos trabalhadores; o quarto, quinto e sexto pontos analisam essas práticas e respetivas dificuldades por tipologia de equipamentos (abrigos e habitações de emergência, habitação apoiada, serviços de suporte móveis e Housing

\footnotetext{
${ }^{1}$ Baptista, I., Benjaminsen, L., Busch-Geertsema, V., \& Pleace, N. (2020). Staffing Homelessness Services in Europe, EOH, Comparative Studies on Homelessness, 10, Brussels: Feantsa. https://www.feantsaresearch.org/en/comparative-studies/2020/12/16/comparative-studies-on$\underline{\text { homelessness-10-staffing-homelessness-services-in-europe?bcParent=763 }}$

2 ampt.goncalves@gmail.com.

${ }^{3}$ Entre os vários estudos comparativos realizados, no âmbito do $\mathrm{EOH}$, vale a pena referir o segundo: Baptista, Isabel; Benjaminsen, Lars; Pleace, Nicholas; Busch-Geetsema, Volker (2012), Counting Homeless People in the 2011, Housing and Population Census, EOH, Comparative Studies on Homelessness 2, Brussels: Feantsa. - Este estudo partiu dos resultados dos Censos Europeus de 2011 que, pela primeira vez, fizeram em todos os Estados-Membros a contabilização das pessoas em situação de sem-abrigo, com o objectivo de obter dados comparáveis, quer em extensão, quer em termos de definição dos grupos de pessoas considerados como sem-abrigo pela tipologia ETHOS, desenvolvida pela FEANSA e pelo EOH.

Cf. https://www.feantsaresearch.org/download/feantsa-studies_02_web8204705709124732086.pdf
}

Copyright (C) 2021 (Gonçalves, A.T.)

Available at http://revistas.rcaap.pt/cct/
Licensed under the Creative Commons Attribution Non-commercial No Derivatives. DOI: $10.15847 /$ cet. 25575
UIDB/03127/2020 
First); o ponto sete dá conta de alguns efeitos imediatos da pandemia sobre os trabalhadores e a gestão dos serviços para as pessoas em situação de sem-abrigo, na Europa ${ }^{4}$ e, no último ponto, apresentam-se os resultados da pesquisa, efetuando, sempre que possível, a comparação entre países e salientando os desafios que se colocam globalmente, nesta área.

\section{Questões de partida e metodologia}

Ao centrar-se em serviços que integram alojamentos destinados a pessoas em situação de sem-abrigo, a pesquisa propôs-se estudar as práticas dos trabalhadores de:

1. Serviços com suporte de baixa intensidade, oferecendo alojamento temporário, de emergência (por exemplo, abrigos de emergência);

2. Serviços de apoio de alta intensidade, para pessoas em situação de sem-abrigo com necessidades complexas, prestando alojamento temporário (por exemplo, albergues e habitação assistida) com pessoal no local;

3. Serviços de suporte móvel, em alojamentos comuns.

A recolha de informação foi efetuada com base num questionário padronizado, distribuído a um grupo de peritos dos 15 países europeus referidos. Os países foram selecionados de acordo com as principais diferenças que se verificam nos sistemas e mercados habitacionais, e nos regimes de bem-estar e prosperidade económica na Europa.

Neste contexto, os peritos entrevistados foram convidados a fornecer informações sobre o seu país: uma panorâmica geral das questões que se colocam ao pessoal que trabalha nos serviços destinados a pessoas em situação de sem-abrigo; problemas específicos na provisão de abrigos de emergência; questões específicas sobre habitação apoiada; problemas específicos relativos a serviços de suporte móvel e relativos à implementação do modelo Housing First. As respostas deviam apoiar-se em exemplos de serviços. Por último, era pedido que referissem os impactes da COVID 19, sobre os trabalhadores e a prestação de serviços a pessoas em situação de sem-abrigo, em julho de 2020.

\section{Principais questões relativas aos trabalhadores}

"People working in the homelessness sector play a vital role, often underappreciated as well as underfunded, as the sector transitions to new ways of supporting homeless people, the need for support for existing and new staff to train and retrain to find new roles and engage with best practice has never been greater.” (Baptista et al., 2020, p. 11)

As experiências dos trabalhadores nos serviços destinados a pessoas em situação de sem-abrigo são variáveis entre os países europeus; contudo, as perspectivas de desenvolvimento de carreira e a segurança no emprego são, em geral, muito limitadas. As próprias qualificações requeridas também variam, quer entre países, quer entre os tipos de serviços prestados.

O programa Housing First tem-se focado em maximizar o alojamento para pessoas em situação de sem-abrigo em habitações comuns, sobretudo na Dinamarca e Finlândia. Noutros países, o foco é garantir primeiro as respostas às necessidades de tratamento, antes da resposta habitacional, nomeadamente na Polónia e Eslovénia. Alguns países, como a República Checa, possuem diversidade de abordagens, enquanto Itália e Portugal se encontram em processo de transição, apostando na expansão do modelo Housing First. Assim, em países nos quais se registava um foco na falta de habitação e um compromisso significativo em termos de recursos, (Dinamarca e Finlândia), o stress das equipas não foi tão referido. Em contrapartida, nos países com recursos escassos e/ ou com

\footnotetext{
${ }^{4}$ Os autores referem que os dados foram recolhidos numa altura em que se pensava que a propagação do vírus estava a recuar, mas pouco depois os níveis de infecção voltaram a aumentar, em muitos países europeus, enquanto o relatório estava a ser escrito.
} 
financiamento instável, combinados com baixos salários e insegurança no emprego, o esgotamento e o stress são mais generalizados, p.e., na Croácia, Grécia, Reino Unido e Portugal, país no qual a aposta nas pessoas em situação de sem-abrigo não se traduziu numa maior afectação de recursos.

Observou-se também necessidade de melhorar o acesso à formação e ao desenvolvimento profissional neste sector, necessidade que pode ser acelerada pela pandemia e pela aposta no modelo Housing First. Os trabalhadores desempenham um papel fundamental neste setor, que é muitas vezes subestimado, afigurando-se essencial uma aposta cada vez maior na sua formação e qualificação.

\section{Impactes iniciais da COVID 19}

"It is therefore clear that society's most vulnerable people who are already in homelessness, poverty, mental illness or addiction are paying the very highest price for this exceptional situation. How can you isolate yourself and keep a physical distance when you have no housing and are forced to beg for survival?" (Baptista et al., 2020, p. 5)

A pesquisa salienta alguns dos impactes iniciais imediatos da COVID 19, que se fizeram sentir sobre os trabalhadores, a gestão dos serviços e as próprias pessoas em situação de sem-abrigo, na Europa, observando-se alguma variabilidade entre países, em termos de medidas adoptadas e tipologia de serviços prestados.

A resposta mais imediata, em países onde se verificava um amplo recurso aos abrigos de emergência como base da prestação de serviços às pessoas sem-abrigo, foi alterar a permanência de utilização apenas noturna, para uma permanência de 24 horas, permitindo às pessoas sem-abrigo um lugar para ficar durante o dia (o que se fez, por exemplo, em Portugal, Grécia, República Checa e Itália), enquanto outros tiveram que ser encerrados. Outras medidas, no âmbito dos abrigos de emergência, foram a redução do número de residentes e, em alguns casos, o encerramento dos próprios serviços. Alguns países reagiram à COVID 19 adoptando uma combinação de hotéis e acomodações temporárias (nomeadamente tendas). Contudo, os impactes de longo prazo são ainda difíceis de avaliar, já que a epidemia não terminou, mas é possível que venham a verificar-se alterações significativas, quer nos empregos disponíveis, quer nos próprios serviços a prestar às pessoas em situação de sem-abrigo. No caso dos trabalhadores, a pandemia acrescentou maior stress e pressão a uma actividade já complexa e repleta de tensões, observando-se que no início, na generalidade dos países, a falta de equipamento de proteção individual para os trabalhadores, constituiu uma das dificuldades a enfrentar.

Refira-se ainda que, de acordo com a pesquisa, em alguns países, a pandemia obrigou os governos a investimentos adicionais nesta área, nomeadamente nos Países Baixos e no Reino Unido, embora neste último tal investimento se tenha apenas dirigido a pessoas que viviam em situações muito precárias e tenha ocorrido após uma década de grandes cortes no setor. Por exemplo, na Bélgica, a testagem em massa de trabalhadores e pessoas em situação de sem-abrigo, foi combinada com programas específicos de apoio financeiro para este e outros setores de ONGs, nomeadamente na região de Bruxelas. No caso da Itália, o governo central não emitiu qualquer orientação específica em termos de intervenção, fazendo com que os serviços e ONGs adotassem os seus próprios protocolos. Os principais desafios eram os de gerir as admissões aos serviços e como isolar quem fosse infectado.

Os países nos quais a prestação de serviços para pessoas em situação de sem-abrigo eram maioritariamente comunitários (geralmente abrigos de emergência e de permanência mais longa), estes encontravam-se sob maior pressão, porque os riscos de infecção eram maiores do que nos casos de serviços com quartos individuais ou apartamentos-estúdio (por exemplo, na Dinamarca e Finlândia), ou no caso de serviços promovidos pelo programa Housing First. No âmbito deste programa, em alguns países os profissionais mantiveram o contacto com os utentes através de vídeochamadas, SMS e WhatsApp, em vez das habituais visitas domiciliárias.

Os autores salientaram que, na generalidade dos países, não houve surtos significativos quer entre trabalhadores, quer entre pessoas em situação de sem-abrigo, enquanto a pesquisa decorreu. 


\section{Principais desafios}

Em termos de resultados, a pesquisa fez emergir alguns dos desafios que se colocam nesta área de trabalho e que se prendem nomeadamente: com o empenhamento dos governos (investimento/ financiamento, recursos e compromisso político); com os traços de mudança que já emergiam antes da pandemia (sobretudo através do modelo Housing First) e os que foram impulsionados pela pandemia, assim como os seus reflexos nos trabalhadores e na organização dos serviços; o que remete para o desafio de consolidação de carreiras e desenvolvimento da formação e qualificação profissionais, assim como para o reconhecimento da importância desta área de trabalho e dos respectivos trabalhadores; e para os desafios de gestão das mudanças neste sector.

Assim, observou-se a importância dos governos nas condições de trabalho com pessoas em situação de sem-abrigo, pois se investirem no setor, em termos financeiros e políticos, as condições de trabalho melhoram para os trabalhadores (maior segurança em termos de salários e de recursos disponíveis para um melhor desempenho). Nos países onde os governos investem de forma limitada e disponibilizam poucos recursos, os trabalhadores sentem-se mais inseguros, são mal pagos e sujeitos a situações de maior stress.

De facto, salários baixos, maior insegurança, escassez de recursos e sensação de precariedade são, grande parte das vezes, a experiência do pessoal que trabalha em serviços para as pessoas em situação de sem-abrigo, na Europa. Como demonstrou esta pesquisa, trabalhar em serviços destinados a pessoas em situação de sem-abrigo pode ser uma atividade compensadora a vários níveis, mas também pode ser fatigante e mal remunerada, provocar esgotamentos, alta rotatividade de pessoal e dificuldades de recrutamento de pessoal.

Observou-se também que os abrigos comunitários de emergência e de permanência longa, constituem o núcleo da prestação de serviços em alguns países, sendo marginais noutros. Os autores salientam, considerando também resultados de estudos anteriores, que o Housing First, assim como outros modelos residenciais, tendem a perdurar, significando que as condições de trabalho e a natureza dos empregos variam significativamente entre os países. Neste contexto, pode dizer-se que um maior envolvimento do estado na orientação e disponibilização de recursos para a implementação de estratégias nacionais nesta área, reduz o risco de trabalho inseguro, devido a baixas remunerações e altos níveis de stress.

A pandemia deu visibilidade a desigualdades habitacionais mais amplas e à falta de habitação acessível, mostrou pontos fortes dos serviços para as pessoas em situação de sem-abrigo, nomeadamente a importância do trabalho que aí se realiza e, embora impulsionado por preocupações mais amplas de saúde pública, permitiu observar que os governos que mais investem podem, de facto, resolver o problema das pessoas em situação de sem-abrigo. É importante capitalizar experiências e resultados alcançados, investindo no aumento da remuneração e na melhoria das condições de trabalho do pessoal.

Refira-se que a natureza do emprego neste sector parece evidenciar mudanças que, devido ao impacte da pandemia, poderão ser mais rápidas e abrangentes do que se esperava. O investimento em formação e desenvolvimento profissional no setor, torna-se fundamental. A oportunidade de carreiras e qualificações profissionais surge, sobretudo, por via do Housing First, modelo que possui serviços bem definidos, mesmo que precise de adaptações às necessidades e locais.

Como salientam os autores,

\footnotetext{
"Homelessness services have always been a mix of amateur, volunteer, semi-professional and professional, both within individual European countries and across Europe as a whole. As we face the consequences of COVID and other pressures that may mean that the homelessness sector experiences major changes, promoting practices and structures that enable those working within homelessness, or who wish to do so, to have clear paths to high standard training may be a route to better working conditions and a stronger and more resilient future for European homelessness services" (Baptista et al., 2020, p. 66)
}

Por último, destaque-se o desafio de saber gerir a mudança, através de consultas e suporte aos trabalhadores, em fase de transição, à medida que os serviços para pessoas em situação de sem-abrigo vão sofrendo alterações. 
Esta interessante pesquisa, traça assim pistas capazes de contribuirem para a concepção e/ ou adequação de políticas públicas, no âmbito do combate e resolução das situações de sem-abrigo, bem como pistas para desenvolvimento e aprofundamento de novas pesquisas.

\section{Livro}

Baptista, I., Benjaminsen, L., Busch-Geertsema, V., Pleace, N. (2020). Staffing Homelessness Services in Europe, EOH, Comparative Studies on Homelessness, 10. Brussels: Feantsa. https://www.feantsaresearch.org/en/comparative-studies/2020/12/16/comparative-studies-on-homelessness-10staffing-homelessness-services-in-europe?bcParent=763. 